\title{
A Novel Donor- $\pi$-Acceptor Type Sensitizer for Dye Sensitized Photochemical Hydrogen Generation
}

\author{
Emre Aslan $1 *$ iD \\ ${ }^{1}$ Selcuk University, Department of Biochemistry, Konya, Turkey \\ *emreaslan89@gmail.com \\ *Orcid: 0000-0002-7672-2873 \\ Received: 22 December 2020 \\ Accepted: 19 April 2021 \\ DOI: $10.18466 /$ cbayarfbe. 844704
}

\begin{abstract}
A novel triphenylamine (TPA) based donor- $\pi$-acceptor (D- $\pi$-A) dye is synthesized and its structural, optical and electrochemical properties are examined by NMR, UV-Vis absorption spectroscopy and cyclic voltammetry methods, respectively. The synthesized D- $\pi$-A dye plays a role as a visible light sensitizer to wide bandgap $\mathrm{TiO}_{2}$ photocatalyst. Photoelectrochemical and photocatalytic hydrogen evolution reaction (HER) are investigated by using $\mathrm{D}-\pi$-A dye sensitized $\mathrm{TiO}_{2}\left(\mathrm{Dye} / \mathrm{TiO}_{2}\right)$ under visible light irradiation in the aqueous triethanolamine (TEOA) sacrificial electron donor medium. Photoelectrochemical properties of $\mathrm{Dye} / \mathrm{TiO}_{2}$ are investigated by using linear sweep voltammetry (LSV) and chronoamperometry (CA) techniques in the aqueous $\mathrm{Na}_{2} \mathrm{SO}_{4} /$ TEOA solution and its transient photoelectrochemical response is reached $90 \mu \mathrm{A} \mathrm{cm}^{-2}$. In addition, photocatalytic hydrogen evolution rates are found out as $0.52 \mathrm{mmol} \mathrm{g}^{-1} \mathrm{~h}^{-}$ ${ }^{1}$ and $1.95 \mathrm{mmol} \mathrm{g}^{-1} \mathrm{~h}^{-1}$ by using of $\mathrm{Dye} / \mathrm{TiO}_{2}$ and $\mathrm{Dye} / \mathrm{TiO}_{2} / \mathrm{Pt}$, respectively, which are obtained by in situ photoreduction of $\mathrm{H}_{2} \mathrm{PtCl}_{6}$ on the Dye/TiO 2 photocatalyst. The mechanism of photochemical HER is explained by electrochemical band levels of the $\mathrm{D}-\pi$-A dye and $\mathrm{TiO}_{2}$ photocatalyst.
\end{abstract}

Keywords: dye sensitization, donor- $\pi$-acceptor dye, hydrogen evolution reaction, photocatalysis, photoelectrochemical

\section{Introduction}

The first hydrogen evolution study was performed by using $\mathrm{TiO}_{2}$ in 1972 with photoelectrochemical method [1]. The development of photocatalytic activity of $\mathrm{TiO}_{2}$ carried out from that day up to the present. However, there are two big drawbacks of $\mathrm{TiO}_{2}$, which are high charge recombination rate and absorption only UV light due to the having wide band gap [2]. These disadvantages can be figured out by using co-catalysts to separate charges efficiently and visible light sensitizers to absorb having low energy light. Decreasing of recombination rate and increasing charge separation efficiency are generally utilized on metallic or semiconductor co-catalysts. Although semiconductor co-catalysts are hard to utilize in the photocatalytic reactions because it has to adjust their energy band levels for electron transfer mechanism. Yet, metallic cocatalysts are very useful for easy-to-handle for photocatalytic reactions. It can be clearly seen that $\mathrm{Pt}$ is the most used and active co-catalyst for the electrocatalytic, photoelectrochemical and photocatalytic hydrogen evolution reaction (HER) [3]. Wide band gap semiconductor such as $\mathrm{TiO}_{2}, \mathrm{ZnO}$ etc. can be used for water splitting to produce both oxygen and hydrogen under high energy light illumination. However, they are very limited to excite by solar spectrum due to their wide band gap. In order to excite these semiconductors for visible-light-driven water splitting can be modified by doping an ion to narrow the band gap or developing alloys to control the band structure. Another effective approach for harvesting more solar irradiation is the utilization of dye sensitizer. Dye sensitized semiconductor for water splitting by using $\mathrm{Ru}(\text { bpy })_{3}{ }^{2+}$ sensitized $\mathrm{Pt} / \mathrm{TiO}_{2} / \mathrm{RuO}_{2}$ derivatives for the first time [4]. In addition, metal centered porphyrin and phthalocyanine analogues common studied for the photocatalytic reactions due to the high absorption of solar spectrum and adjustable energy levels $[5,6]$. Then, metal-free sensitizers have been recently developed for the photocatalytic reactions because of its tunable structure and light absorption region, variety and low-cost. Especially, xanthene dyes and its derivates have been utilized for photocatalytic hydrogen evolution as the efficient and stable sensitizers [7-9]. Xanthene dyes absorb solar light between 400 $600 \mathrm{~nm}$ at the $490-560 \mathrm{~nm}$ absorption peaks, which is similar to Ru-complex dyes, as alternatives to expensive 
Ru-complexes. They found that heavy-halogenated xanthenes have high quantum efficiency for hydrogen evolution, however, they tend to photodehalogenate and instabilities [10]. Due to the increasing photocatalytic activities and stabilities, new class of sensitizers, donor$\pi$-acceptor (D- $\pi$-A) dyes developed. They have high intermolecular charge transfer (ICT) ability and configurable absorption, which can be provided high photocatalytic efficiencies and absorption of solar spectrum [11-14]. Recently, donor- $\pi$-acceptor (D- $\pi$-A) dyes great attention for the both dye sensitized solar cells (DSSC) and photochemical energy conversion reactions because of the mentioned properties above. The high ICT performances of $\mathrm{D}-\pi-\mathrm{A}$ dyes reduce the recombination rates [11]. Photocatalytic activities of D$\pi$-A dyes can be changed by different structural properties such as hydrophilicity and steric effect, the amount of dye load, spacer length and the number of anchoring groups of dyes [15-20]. D- $\pi$-A dyes consisted of donor groups, $\pi$ bridge and acceptor groups. Generally, triphenylamine (TPA) based donor moieties have recently been preferred due to prevent aggregations from its non-plannar structures by its ease in oxidation of the nitrogen center and own the ability to transport charge carriers via the radical cation species with high stability [21]. Kang research group investigated photocatalytic HER performance by changing chain length in the EDTA solution and reported the dependence on the hydrophilic/hydrophobic character of the binding group to the TPA donor moieties [15, 17]. Tiwari et al. reported that changing $\pi$-spacer groups are effectively prevented the aggregation between dye molecules. In addition it provides an well surface protection, which decrease the charge recombination in photocatalytic HER [22]. Li et al. examined by changing of different electronegativities of atom in the $\pi$-spacer groups and figured out having high electronegative atoms increased photocatalytic activity [23]. Dessi et al. investigated that photocatalytic HER performances of TPA based D- $\pi$-A dyes are improved by increasing donor moieties with the hexyloxy chains attached to the on its terminal TPA group [24]. Moreover, our research group were reported TPA based $\mathrm{D}-\pi$-A dye sensitized $\mathrm{TiO}_{2}$ photocatalysts for photocatalytic and photoelectrochemical hydrogen evolution in the triethanolamine (TEOA) sacrificial electron donor media under solar irradiation [25-28]. In these works, firstly, photocatalytic and photoelectrochemical activities on the HER were examined in the absence and presence of extra electron donating two hexyloxy groups on the TPA. Herein, dye without hexyloxy groups displayed more photochemical activity due to its advanced optical absorption and ICT properties [25]. Then, the effect of $\pi$-spacer group has investigated in the photocatalytic HER and figured out that adding $\pi$-spacer group eventuated higher photocatalytic HER activity [26]. Finally, the very similar TPA based D- $\pi$-A dyes were studied by our research group and examined the effect of acceptor and spacer group on the photocatalytic and photoelectrochemical HER activities. Here, having high electronegativity of an atom in the spacer group increased the photochemical HER activity [27]. In addition, while it suggested that increasing the acceptor strength raise the photocatalytic HER performance, adversely affect the HER activity because it give rise to aggregation of dyes on the $\mathrm{TiO}_{2}$ photocatalyst [28].

In this study, a novel donor- $\pi$-acceptor (D- $\pi$-A) dye synthesized for the photochemical hydrogen generation from water splitting. Optical and electrochemical properties of the synthesized D- $\pi$-A dye were investigated in order to explain the mechanism of photocatalytic hydrogen evolution. $\mathrm{D}-\pi$-A dye was used to sensitize $\mathrm{TiO}_{2}$ photocatalyst. Hydrogen evolution is examined by using photoelectrochemical and photocatalytic methods in the presence of triethanolamine (TEOA) as a sacrificial electron donor under visible light illumination.

\section{Materials and Methods \\ 2.1. Materials}

All solvents and reagents were purchased as puriss quality. Dichloromethane $\left(\mathrm{CH}_{2} \mathrm{Cl}_{2}\right)$, chloroform $\left(\mathrm{CHCl}_{3}\right)$, n-hexane, tetrahydrofuran (THF), 1,2dimethoxyethane (DME), [1,10bi(diphenylphospino)ferrocene]dichloro palladium (II) and tetrabutylammonium hexafluorophosphate $\left(\mathrm{Bu}_{4} \mathrm{NPF}_{6}\right)$ were supplied from Sigma-Aldrich. Potassium carbonate and potassium hydroxide were purchased from Riedel-de Haen. Column chromatography was carried out by using Merck silica gels $(230-400$ mesh). Acetonitrile (ACN), tetrahydrofuran (THF), triethanolamine (TEOA), hydrochloric acid $(\mathrm{HCl})$, sodium hydroxyde $(\mathrm{NaOH})$ and sodium sulfate $\left(\mathrm{Na}_{2} \mathrm{SO}_{4}\right)$ were obtained by Merck for hydrogen generation experiments.

\subsection{Synthesis of $D-\pi-A$ dye}

2.2.1. Synthesis of 4 ' - \{6- [5- (4- \{bis [4- (hexyloxy) phenyl] amino $\}$ phenyl) -4- (2-ethylhexyl) -2thienyl] -1,2,4,5-tetrazine- 3-yl $\}-3$ '- (2ethylhexyl) -2,2'-bithiophene-5-carbonitrile

4-(5-(6-(5-bromo-4-ethylhexyl)thiophen-2-yl)-1,2,4,5tetrazin-3-yl)-3-(2-ethylhexyl) thiophene-2-yl)-N, Nbis(4-(hexyloxy) phenyl)aniline (115 mg; $0.116 \mathrm{mmol})$ and 5- (4,4,5,5-tetramethyl-1,3,2-dioxaborolan-2-yl) thiophene-2-carbonitrile (38 $\mathrm{mg} ; 0.164 \mathrm{mmol})$ were dissolved in anhydrous DME and $\mathrm{K}_{2} \mathrm{CO}_{3}(54 \mathrm{mg} ; 0.394$ $\mathrm{mmol}$ ) (in $0.5 \mathrm{~mL}$ water) was added. After the solution was saturated with argon gas, $\mathrm{Pd}(\mathrm{ddpf}) \mathrm{Cl}_{2}(5.1 \mathrm{mg}$; $0.007 \mathrm{mmol}$ ) was added. The reaction was stirred for $48 \mathrm{~h}$ at $90{ }^{\circ} \mathrm{C}$, then cooled to room temperature. The mixture was poured into water $(30 \mathrm{~mL})$ and extracted with chloroform and dichloromethane. Organic phases were combined and evaporated by rotary. The product was purified with column chromatography (silica gel, $\mathrm{CH}_{2} \mathrm{Cl}_{2}: \mathrm{MeOH}$ 15:0.5). 
2.2.2. Synthesis of $4^{\prime}-\{$ - 6- [5- (4- \{bis [4- (hexyloxy) phenyl] amino $\}$ phenyl) -4- (2-ethylhexyl) -2thienyl] -1,2,4,5-tetrazine- 3-yl\} -3 '- (2ethylhexyl) $\quad-2,2^{\prime}$-bitiophene-5-carboxylic acid (D- $\pi$-A dye)

5 '- \{6- [5- (4- \{bis [4- (hexyloxy) phenyl] amino $\}$ phenyl) -4- (2-ethylhexyl) -2-thienyl] -1,2,4,5-tetrazine3-yl \} -3'- (2-ethylhexyl) -2,2'-bitiophene-5-carbonitrile (76.4 mg; $0.075 \mathrm{mmol}$ ) was dissolved in $\mathrm{THF} / \mathrm{MeOH}$ $(1: 1,10 \mathrm{ml})$ in the two necked flask. $2 \mathrm{M} \mathrm{KOH}(0.19$ $\mathrm{ml}$ ) was added into the mixture and refluxed for $48 \mathrm{~h}$ The reaction was controlled with TLC and neutralized with $\mathrm{HCl}$. The crude product was extracted with water $/ \mathrm{CH}_{2} \mathrm{Cl}_{2}$ (1:2). The product was purified with a silica gel column chromatography $\left(\mathrm{CH}_{2} \mathrm{Cl}_{2}\right.$, $\mathrm{CH}_{2} \mathrm{Cl}_{2} / \mathrm{MeOH} 15: 1$ ) (Figure 1).

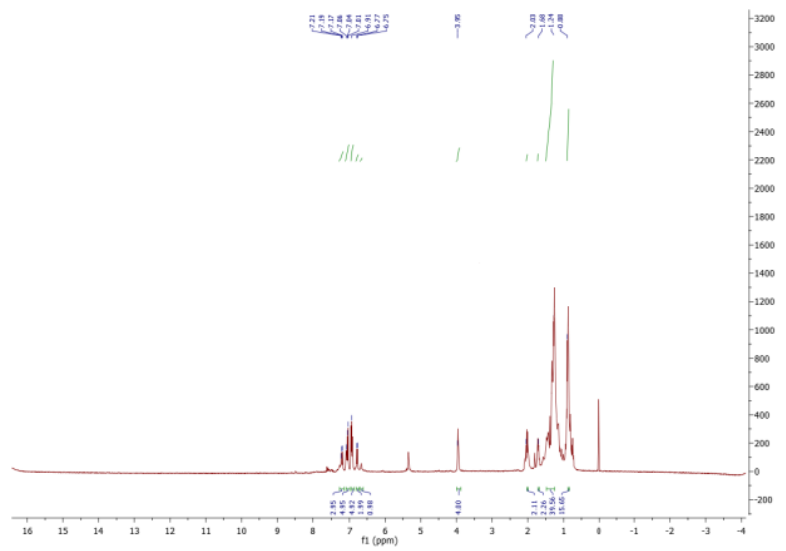

Figure 1. NMR spectrum of synthesized D- $\pi$-A dye

\subsection{Optical and electrochemical experiments}

Optical and electrochemical properties of $\mathrm{D}-\pi$-A dye have been investigated by Shimadzu UV-1800 UV-Vis absorption spectrophotometer and $\mathrm{CH}$ 760D potentiostat, respectively. Absorption spectrum was performed by using $10^{-5} \mathrm{M}$ dye solution in tetrahydrofuran (THF). Molar extinction coefficients $(\varepsilon)$ of dyes have been calculated by using Beer-Lambert law [29]. Electrochemical properties and band diagrams of dye were examined by cyclic voltammetry technique in acetonitrile (ACN) by using $0.1 \quad \mathrm{M}$ tetrabutylammonium hexafluorophosphate $\left(\mathrm{Bu}_{4} \mathrm{NPF}_{6}\right)$ solution as supporting electrolyte with standard three electrode setup using glassy carbon electrode (GCE), Pt wire and $\mathrm{Ag} / \mathrm{AgCl}$ electrodes act as working, counter and reference electrodes, respectively. HOMO and LUMO levels were calculated from oxidation and reduction potentials, respectively.

\subsection{Dye sensitization process}

$\mathrm{TiO}_{2}$ coated fluorine doped tin oxide (FTO) glass electrode and powdered $\mathrm{TiO}_{2}$ are used for the photoelectrochemical and photocatalytic hydrogen evolution reaction (HER), respectively. The dye sensitization process is the same for the both coated electrode and powdered $\mathrm{TiO}_{2}$. Firstly, $\mathrm{TiO}_{2}$ species were calcinated at $450{ }^{\circ} \mathrm{C}$ for 45 minutes in order to eliminate adsorbed water and organic impurities on the surface of $\mathrm{TiO}_{2}$ before the sensitization process. After the calcination, $\mathrm{TiO}_{2}$ species have been added into the dye solution $\left(10^{-5} \mathrm{M}\right.$ in $\left.\mathrm{THF}\right) . \mathrm{TiO}_{2}$ electrode was kept overnight in the dye solution. Powdered $\mathrm{TiO}_{2}$ stirred with magnetic mixer overnight in the dye solution under dark conditions. Then dye sensitized $\mathrm{TiO}_{2}$ species were rinsed by THF and ethanol three times to remove unbinding dye molecules. Finally, dye sensitized $\mathrm{TiO}_{2}$ species were kept under room condition for drying to use in the photoelectrochemical and photocatalytic hydrogen evolution experiments.

\subsection{Photoelectrochemical and photocatalytic HER experiments}

Photoelectrochemical properties of dye sensitized $\mathrm{TiO}_{2}$ electrode were investigated in the $0.1 \mathrm{M} \mathrm{Na}_{2} \mathrm{SO}_{4}$ and $5 \%$ TEOA solution under the LED illumination by on/off cycles. Herein, standard three electrode setup is consisted of dye sensitized $\mathrm{TiO}_{2}$, Pt plate and $\mathrm{Ag} / \mathrm{AgCl}$ electrodes act as the photanode working electrode, counter electrode and reference electrode, respectively. Photocatalytic HER experiments were carried out by using powdered $\mathrm{TiO}_{2}$ sensitized by $\mathrm{D}-\pi$-A dye in the presence of oxygen-free 5\% TEOA solution. This emulsion was prepared in the glove-box and reaction cell is sealed by rubber septum. The sealed reaction cell was put onto solar simulator (Solar Light XPS-300TM) and stirring magnetically to occur homogenous photocatalytic reaction. Then, sampling of head space gas taken by gas tight syringe and injected into gas chromatography in order to calculate generated hydrogen amount by using standard calibration curve changing $0.1 \%$ and $5 \%$ concentration of $\mathrm{H}_{2}$ in $\mathrm{N}_{2}$.

\section{Results and Discussion \\ 3.1. Synthesis of D- $\pi$-A dye}

Herein the synthesized D- $\pi$-A dye was used as visible light sensitizer. 3,6-bis [4-methylthien-2-yl]-stetrazine (I) was synthesized according to literature [27, 28]. 4'\{6-[5-(4-\{bis [4-(hexyloxy)phenyl]amino $\}$ phenyl)-4-(2ethylhexyl)-2-thienyl]-1,2,4,5-tetrazine- 3-yl\}-3'-(2ethylhexyl)-2,2'-bithiophene-5-carbonitrile was synthesized between 4-(5-(6-(5-bromo-4ethylhexyl)thiophen-2-yl)-1,2,4,5-tetrazin-3-yl)-3-(2ethylhexyl) thiophene-2-yl)-N, N-bis(4-(hexyloxy) phenyl)aniline and 5- (4,4,5,5-tetramethyl-1,3,2dioxaborolan-2-yl) thiophene-2-carbonitrile by the Suzuki-Miyaura coupling reaction. The intermediate molecule was converted to D- $\boldsymbol{\pi}-\mathbf{A}$ dye by the Knoevenagel condensation reaction. 


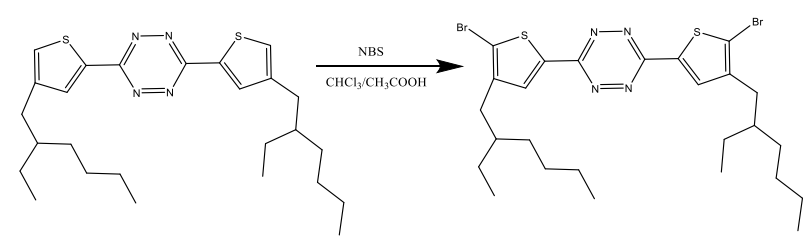

(I)

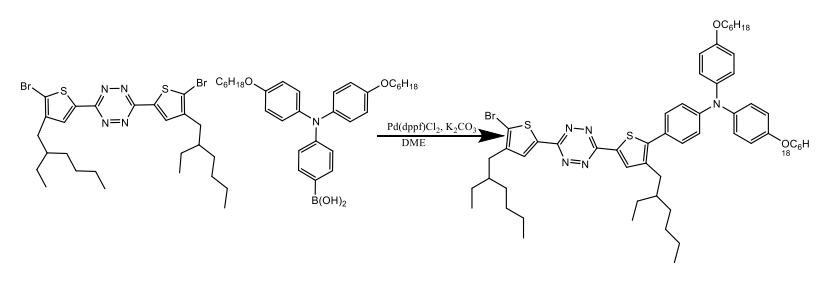

(II)

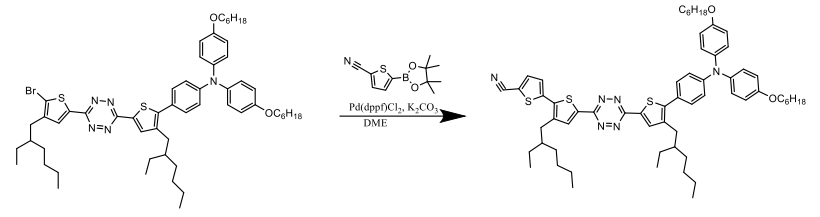

(III)

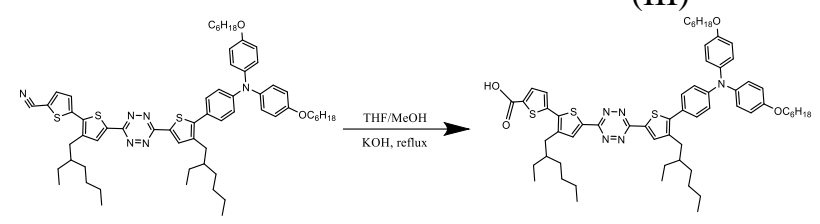

$D-\pi-A$ dye

Scheme 1. Synthesis procedure and molecular structure of D- $\pi$-A dye

\subsection{Optical and electrochemical properties of $D-\pi-A$ dye}

Optical properties of $\mathrm{D}-\pi$-A dye were investigated by UV-Vis absorption spectra. As shown in figure $\mathbf{2 a}$, two peaks were observed at the $291 \mathrm{~nm}$ and $345 \mathrm{~nm}$ originated from localized $\pi-\pi^{*}$ and delocalized $\pi-\pi^{*}$ transitions, respectively, because of intramolecular charge transfer (ICT) properties between donor (triphenylamine) and acceptor (carboxylic acid) groups [30]. Besides, molar absorption coefficient $(\varepsilon)$ of the sensitizer was calculated as $1800 \mathrm{M}^{-1} \mathrm{~cm}^{-1}(345 \mathrm{~nm})$ by Lambert-Beer Law [29]. Electrochemical properties of sensitizer were investigated by cyclic voltammetry method using glassy carbon electrode (GCE), Pt wire and $\mathrm{Ag} / \mathrm{AgCl}$ electrodes as working, counter and reference electrodes, respectively, in the $0.1 \mathrm{M}$ tetrabutylammonium hexafluorophosphate $\left(\mathrm{Bu}_{4} \mathrm{NPF}_{6}\right)$ solution in acetonitrile (ACN) as a supporting electrolyte. As displayed in figure $\mathbf{2 b}$, there is one oxidation peak in the voltammogram at the positive region $(0.85 \mathrm{~V})$ because of donor moiety of triphenylamine group. In addition, the peaks at the negative region in the voltammogram are correspond to $\pi$ group $(-1.00 \mathrm{~V}$ and $-1.41 \mathrm{~V})$ and acceptor group $(-1.85$ $\mathrm{V}$, originated from acceptor moieties of carboxylic acid). HOMO and LUMO levels of sensitizer were calculated vs. vacuum level according to equations below [31] from oxidation and reduction potentials, which were found as $-5.25 \mathrm{eV}$ and $-3.40 \mathrm{eV}$.

$\mathrm{E}_{\mathrm{LUMO}}=-\mathrm{e}\left(\mathrm{E}_{\mathrm{red}}+4.4\right)$
$\mathrm{E}_{\text {HOMO }}=-\mathrm{e}\left(\mathrm{E}_{\mathrm{ox}}+4.4\right)$

The electrochemical band gap was figured out as 1.85 $\mathrm{eV}$ by subtraction between HOMO and LUMO energy levels. The optical and electrochemical properties of sensitizer in good agreement with before published studies about resemble D- $\pi$-A dyes [25-28, 32]. The whole optical and electrochemical parameters of D- $\pi-A$ dye are given in the Table $\mathbf{1}$.
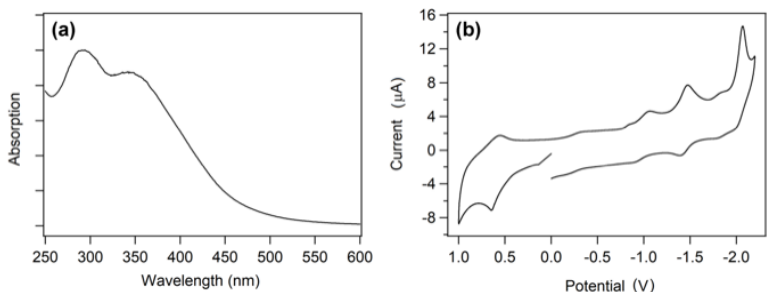

Figure 2. (a) UV-Vis absorption spectra of dye in the THF and (b) cyclic voltammogram of dye by using 0.1 $\mathrm{M} \mathrm{Bu}_{4} \mathrm{NPF}_{6}$ solution in the $\mathrm{ACN}$ as supporting electrolyte.

Table 1. Optical and electrochemical parameters of D$\pi$-A dye

\begin{tabular}{|c|c|}
\hline & Dye \\
\hline $\begin{array}{l}\text { Absorption Wavelength }(\lambda) / \\
n m\end{array}$ & 345 \\
\hline $\begin{array}{l}\text { Molar Absorption Coefficient } \\
(\varepsilon) / \mathrm{M}^{-1} \mathrm{~cm}^{-1}\end{array}$ & 1800 \\
\hline Oxidation Potential / V & 0.85 \\
\hline Reduction Potentials / V & $\begin{array}{lll}-1.00 \quad / \quad- \\
1.41 & \end{array}$ \\
\hline HOMO energy level / eV & -5.25 \\
\hline LUMO energy level / eV & -3.40 \\
\hline
\end{tabular}

\subsection{Photoelectrochemical and photocatalytic hydrogen evolution}

Dye sensitized photochemical water splitting (WS) reactions is named as artificial photosynthesis in the literature studies due to the mimicking the Z-scheme of natural photosynthesis by solar energy into chemical energy [13]. In this study, D- $\pi$-A dye has been used as a visible light sensitizer in the both photoelectrochemical and photocatalytic hydrogen evolution reaction from WS. Herein, photochemical reactions have been carried out in the presence of scavenger electron donor triethanolamine (TEOA) in order to increase hydrogen generation by blocking oxygen evolution because it can 
be reduced in the presence of generated $\mathrm{O}_{2}$ and inhibited $\mathrm{H}_{2}$ generation due to the more positive reduction potential $\left(\mathrm{E}_{\mathrm{O} 2 / \mathrm{H} 2 \mathrm{O}}^{\mathrm{o}}=1.23 \mathrm{~V}\right.$ and $\mathrm{E}_{\mathrm{H}+\mathrm{H} 2}^{\mathrm{o}}=0.00 \mathrm{~V}$ vs. NHE). In this study, firstly, photoelectrochemical hydrogen evolution experiments have been carried out by linear sweep voltammetry (LSV) and chronoamperometry (CA) techniques by using $\mathrm{TiO}_{2}$ and D- $\pi$-A dye sensitized $\mathrm{TiO}_{2}$ coated FTO electrodes. Herein, dye sensitized $\mathrm{TiO}_{2}$ coated FTO, Pt plate and $\mathrm{Ag} / \mathrm{AgCl}$ electrodes as working, counter and reference electrodes, respectively, under on/off illumination cycles in the oxygen-free aqueous $0.1 \mathrm{M} \mathrm{Na} \mathrm{NO}_{4}$ (supporting electrolyte) / 5\% TEOA (electron donor) solution. Herein, working electrode utilized as the photoanode because n-type semiconductor electrodes generally participate in photoanode preparation. In the photoelectrochemical system, D- $\pi$-A dye excited by light and generated holes and excited electrons. These excited electrons were transferred into Pt plate counter electrode (cathode) to generate hydrogen. Then, the holes in the $\mathrm{D}-\pi$-A dye on $\mathrm{TiO}_{2}$ photoanode were refilled by scavenger electron donor TEOA to regenerate the photoelectrochemical system. The hydrogen evolution rates are associated with transient current density and it is directly based on efficiency of intramolecular charge transfer (ICT) properties and absorption of sensitizers on the $\mathrm{TiO}_{2}$ photoanode [12]. Photoelectrochemical properties of D- $\pi$-A dye sensitized $\mathrm{TiO}_{2}$ electrode was firstly investigated by linear sweep voltammetry (LSV) under visible light illumination with $2 \mathrm{~s}$ on/off cycles as shown in figure 3a. The $\mathrm{D}-\pi$-A dye sensitized $\mathrm{TiO}_{2}$ electrode displayed well-stability between $+0.5 \mathrm{~V}$ and $-0.4 \mathrm{~V}$ potential window. After that, CA experiments have been performed in the absence and presence of dye on the $\mathrm{TiO}_{2}$ electrodes. In the absence of dye, only $\mathrm{TiO}_{2}$

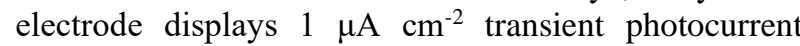
density, which was also unstable and inefficient photocurrent character. However, enhancing and stable transient photocurrent density have been monitored by using dye sensitized $\mathrm{TiO}_{2}$ electrode, which was approximately $90 \mu \mathrm{A} \mathrm{cm} \mathrm{cm}^{-2}$, during the on/off cycles (Figure 3a). These photoactivity and photostability can be originated from absorption of light and intramolecular charge transfer (ICT) properties of D- $\pi$ A dye, respectively (vide supra). These results are in accordance with the photocatalytic experiment results (vide infra).
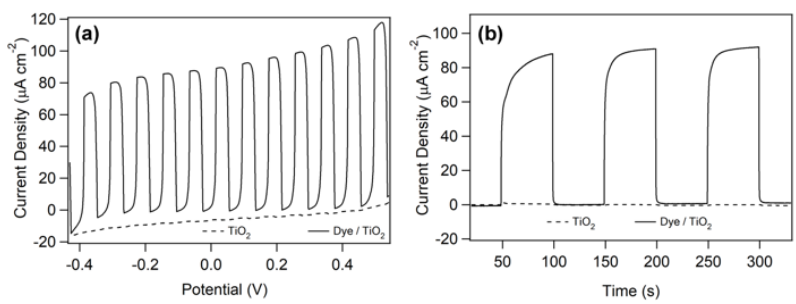

Figure 3. Transient photocurrent response of $\mathrm{TiO}_{2}$ and D- $\pi$-A dye sensitized $\mathrm{TiO}_{2}$ coated FTO electrodes by using (a) LSV and (b) CA techniques.
Photocatalytic HER properties of $\mathrm{D}-\pi$-A sensitized $\mathrm{TiO}_{2}$ have been examined in the aqueous TEOA solution $(5 \%)$ at $\mathrm{pH}=9$, which is determined according to our previous studies with very familiar D- $\pi$-A dyes [25-28], under solar irradiation $(\lambda \geq 420 \mathrm{~nm})$ with magnetically stirring for homogenous reaction condition. The amounts of hydrogen generation are shown against time by using $\mathrm{Dye} / \mathrm{TiO}_{2}$ and $\mathrm{Dye} / \mathrm{TiO}_{2} / \mathrm{Pt}$, which $\mathrm{Pt}$ is occurred by photoreduction of $\mathrm{H}_{2} \mathrm{PtCl}_{6}$ on the Dye/TiO photocatalyst, in figure 4. The HER rates of $\mathrm{Dye} / \mathrm{TiO}_{2}$ and $\mathrm{Dye} / \mathrm{TiO}_{2} / \mathrm{Pt}$ were found as $0.52 \mathrm{mmol} \mathrm{g}^{-1} \mathrm{~h}^{-1}$ and $1.95 \mathrm{mmol} \mathrm{g}^{-1} \mathrm{~h}^{-1}$, respectively. After eight hours of photocatalytic reaction $3.00 \mathrm{mmol} \mathrm{g}^{-1}$ and $19.23 \mathrm{mmol}$ $\mathrm{g}^{-1}$ hydrogen were produced by using $\mathrm{Dye} / \mathrm{TiO}_{2}$ and Dye/ $/ \mathrm{TiO}_{2} / \mathrm{Pt}$, respectively. These results displayed that very stable hydrogen generation rate in the absence and presence of $\mathrm{Pt}$ co-catalyst, which can be explained by well intramolecular charge transfer (ICT) of D- $\pi$-A type dyes [12].

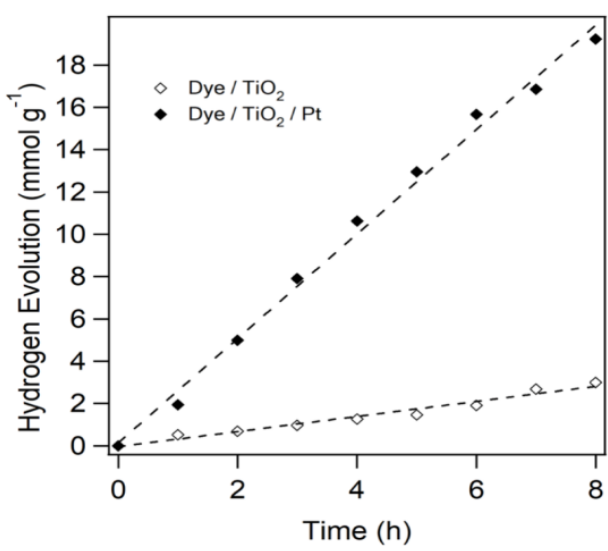

Figure 4. Photocatalytic hydrogen evolution against time by using $\mathrm{Dye} / \mathrm{TiO}_{2}$ and $\mathrm{Dye} / \mathrm{TiO}_{2} / \mathrm{Pt}$ in the aqueous TEOA $(5 \%)$ electron donor solution.

The photocatalytic activities of different D- $\pi$-A dye sensitized $\mathrm{TiO}_{2}$ photocatalysts are compared in the same sacrificial media by changing different sensitizers according to our previous studies. These results display that $\mathrm{D}-\pi-\mathrm{A}$ dye in this study gives comparable HER rates in the similar conditions.

Table 2. The comparison of HER rates for D- $\pi$-A dye with other reported similar structured dye sensitized photocatalytic HER studies

\begin{tabular}{|c|c|c|}
\hline Photocatalysts & $\begin{array}{l}\text { HER Rates } \\
\left(\mu \mathrm{molg}^{-1} \mathbf{h}^{-1}\right)\end{array}$ & References \\
\hline $\mathrm{TiO}_{2} / \mathrm{MZ}-235$ & 531 & \multirow[b]{2}{*}{ [25] } \\
\hline $\mathrm{TiO}_{2} / \mathrm{MZ}-341$ & 661 & \\
\hline $\mathrm{TiO}_{2} / \mathrm{MC}-32$ & 121 & \multirow{2}{*}{ [26] } \\
\hline $\mathrm{TiO}_{2} / \mathrm{MZ}-048$ & 212 & \\
\hline $\mathrm{TiO}_{2} / \mathrm{MK}-3$ & 427 & \multirow{2}{*}{ [27] } \\
\hline $\mathrm{TiO}_{2} / \mathrm{MK}-4$ & 675 & \\
\hline $\mathrm{TiO}_{2} / \mathrm{MK}-2$ & 565 & \multirow{2}{*}{ [28] } \\
\hline $\mathrm{TiO}_{2} / \mathrm{MK}-8$ & 374 & \\
\hline $\mathrm{D}-\pi-\mathrm{A} / \mathrm{TiO}_{2}$ & 520 & This work \\
\hline
\end{tabular}




\subsection{Mechanism of HER}

The mechanism of dye sensitized hydrogen evolution is figured out by electron transfer mechanism, which generally explained by three main steps. First step is the absorption of light by D- $\pi$-A dye and electrons at the HOMO $(0.85 \mathrm{~V})$ level are excited to LUMO $(-1.00 \mathrm{~V})$ level. Then, the second step are that the photoexcited electrons are injected into conduction band of $\mathrm{TiO}_{2}(-0.5$ V). It can be favorable because $\mathrm{CB}$ of $\mathrm{TiO}_{2}$ more positive than LUMO level of dye. The last step is that the excited electrons $\left(\mathrm{e}^{-}\right)$on the $\mathrm{CB}$ of $\mathrm{TiO}_{2}$ reduced of adsorbed proton onto $\mathrm{TiO}_{2}$ photocatalyst to generate $\mathrm{H}_{2}$ gas (or constitute $\mathrm{Pt}$ co-catalyst on the $\mathrm{TiO}_{2}$ in the presence of $\mathrm{H}_{2} \mathrm{PtCl}_{6}$ ), also the hole $\left(\mathrm{h}^{+}\right)$on the HOMO level of dye can be refilled in the same time by giving electrons by electron donor TEOA to regenerate the photocatalytic HER system (Figure 5).

$$
\begin{aligned}
& \text { Dye }+h v \rightarrow \mathrm{e}_{\text {LUMo }}^{-}+\mathrm{h}^{+}{ }_{\text {HOMO }} \\
& \mathrm{e}_{\text {LUMO }^{-}}+\mathrm{TiO}_{2} \rightarrow \mathrm{TiO}_{2} * \\
& \mathrm{TiO}_{2} *+\mathrm{H}^{+} \rightarrow 1 / 2 \mathrm{H}_{2}+\mathrm{TiO}_{2} \\
& \mathrm{TEOA}^{+}+\mathrm{h}^{+}{ }_{\text {HOMO }} \rightarrow \mathrm{TEOA}^{+}
\end{aligned}
$$

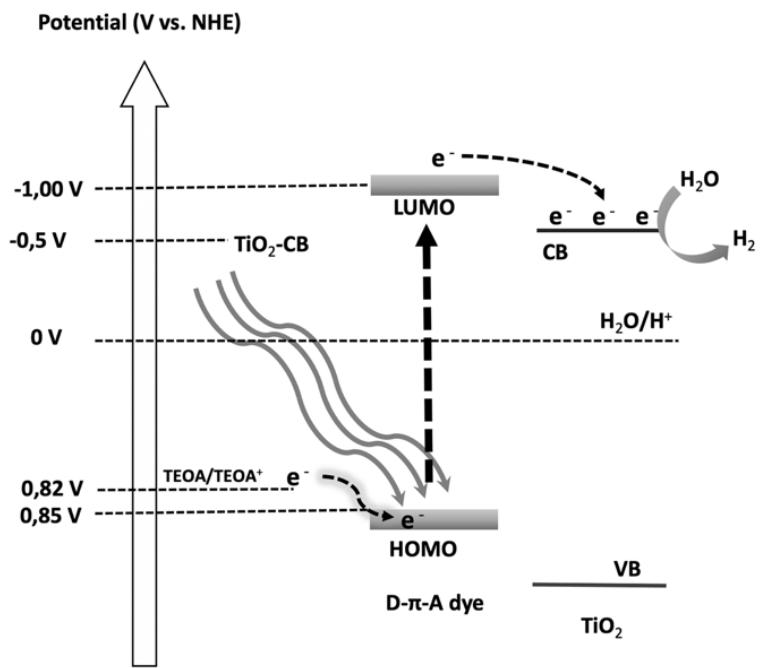

Figure 5. Proposed mechanism of photocatalytic HER by using $\mathrm{D}-\pi$-A dye sensitized $\mathrm{TiO}_{2}$

\section{Conclusion}

A novel D- $\pi$-A dye was synthesized and its optical and electrochemical properties were investigated in order to determine light absorption characteristics and electrochemical band levels for explaining reaction mechanism. Photoelectrochemical and photocatalytic HER activities were investigated by $D-\pi$-A dye sensitized $\mathrm{TiO}_{2}$. Herein, advanced photochemical activity of $\mathrm{Dye} / \mathrm{TiO}_{2}$ photocatalyst can be explained by ICT properties of $\mathrm{D}-\pi-\mathrm{A}$ dyes for hydrogen evolution. In addition, $\mathrm{Dye} / \mathrm{TiO}_{2}$ the photocatalytic activity of Dye/ $/ \mathrm{TiO}_{2}$ photocatalyst was dramatically increased adding in situ photodeposited co-catalyst Pt. The stabilities of photocatalytic HER were maintained during the reaction by using both $\mathrm{Dye} / \mathrm{TiO}_{2}$ and Dye/ $/ \mathrm{TiO}_{2} / \mathrm{Pt}$. This study brings on the novel energy application based on light absorption by $\mathrm{D}-\pi$-A dyes.

\section{Acknowledgement}

This work has been done under the umbrella of the Selçuk University Scientific Research Projects (Grant number: 20401033) also accumulation of knowledge from TÜBITAK-1003 project (Grant number: 215M309). In addition, the author would like to thank to Assoc. Prof. Dr. Mustafa Can from İzmir Katip Çelebi University for the synthesis and characterization of dye molecule, as well as Prof. Dr. Imren Hatay Patir from Selçuk University for the valuable guidance and contributions on the use of laboratory equipment.

\section{Author's Contributions}

Emre Aslan: Drafted and wrote the manuscript, performed the experiment and result analysis.

\section{Ethics}

There are no ethical issues after the publication of this manuscript.

\section{References}

1 Fujishima, A. and K. Honda, Electrochemical Photolysis of Water at a Semiconductor Electrode. Nature, 1972. 238(5358): p. 37-38.

2 Ma, Y., X. Wang, Y. Jia, X. Chen, H. Han, and C. Li, Titanium Dioxide-Based Nanomaterials for Photocatalytic Fuel Generations. Chemical Reviews, 2014. 114(19): p. 9987-10043.

3 Huang, J.-F., Y. Lei, T. Luo, and J.-M. Liu, Photocatalytic H2 Production from Water by Metal-free Dye-sensitized $\mathrm{TiO} 2$ Semiconductors: The Role and Development Process of Organic Sensitizers. ChemSusChem, 2020. 13(22): p. 5863-5895.

4 Borgarello, E., J. Kiwi, E. Pelizzetti, M. Visca, and M. Grätzel, Photochemical cleavage of water by photocatalysis. Nature, 1981. 289: p. $158-160$

5 Martín-Gomis, L., F. Fernández-Lázaro, and Á. Sastre-Santos, Advances in phthalocyanine-sensitized solar cells (PcSSCs). Journal of Materials Chemistry A, 2014. 2(38): p. 15672-15682.

6 Urbani, M., M. Grätzel, M.K. Nazeeruddin, and T. Torres, MesoSubstituted Porphyrins for Dye-Sensitized Solar Cells. Chemical Reviews, 2014. 114(24): p. 12330-12396.

7 Kong, C., S. Min, and G. Lu, Dye-Sensitized NiSx Catalyst Decorated on Graphene for Highly Efficient Reduction of Water to Hydrogen under Visible Light Irradiation. ACS Catalysis, 2014. 4(8): p. 2763-2769.

8 Joseph, K.L.V., J. Lim, A. Anthonysamy, H.-i. Kim, W. Choi, and J.K. Kim, Squaraine-sensitized composite of a reduced graphene oxide/TiO2 photocatalyst: $\pi-\pi$ stacking as a new method of dye anchoring. Journal of Materials Chemistry A, 2015. 3(1): p. 232-239.

9 Nada, A.A., H.A. Hamed, M.H. Barakat, N.R. Mohamed, and T.N. Veziroglu, Enhancement of photocatalytic hydrogen production rate using photosensitized $\mathrm{TiO} 2 / \mathrm{RuO} 2-\mathrm{MV} 2+$. 
International Journal of Hydrogen Energy, 2008. 33(13): p. 3264-3269.

10 Shimidzu, T., T. Iyoda, and Y. Koide, An advanced visiblelight-induced water reduction with dye-sensitized semiconductor powder catalyst. Journal of the American Chemical Society, 1985. 107(1): p. 35-41.

$11 \mathrm{Wu}, \mathrm{Y}$. and W. Zhu, Organic sensitizers from D- $\pi$-A to D-A- $\pi$ A: effect of the internal electron-withdrawing units on molecular absorption, energy levels and photovoltaic performances. Chemical Society Reviews, 2013. 42(5): p. 2039 2058 .

$12 \mathrm{Yu}, \mathrm{Z}$., F. Li, and L. Sun, Recent advances in dye-sensitized photoelectrochemical cells for solar hydrogen production based on molecular components. Energy \& Environmental Science, 2015. 8(3): p. $760-775$

13 Zhang, X., T. Peng, and S. Song, Recent advances in dyesensitized semiconductor systems for photocatalytic hydrogen production. Journal of Materials Chemistry A, 2016. 4(7): p. 2365-2402.

14 Hardin, B.E., H.J. Snaith, and M.D. McGehee, The renaissance of dye-sensitized solar cells. Nature Photonics, 2012. 6: p. 162.

15 Lee, S.-H., Y. Park, K.-R. Wee, H.-J. Son, D.W. Cho, C. Pac W. Choi, and S.O. Kang, Significance of Hydrophilic Characters of Organic Dyes in Visible-Light Hydrogen Generation Based on TiO2. Organic Letters, 2010. 12(3): p. 460-463

Jae-Hong, K. and A. Kwang-Soon, Tri-Branched TriAnchoring Organic Dye for Visible Light-Responsive DyeSensitized Photoelectrochemical Water-Splitting Cells. Japanese Journal of Applied Physics, 2010. 49(6R): p. 060219.

17 Han, W.-S., K.-R. Wee, H.-Y. Kim, C. Pac, Y. Nabetani, D Yamamoto, T. Shimada, H. Inoue, H. Choi, K. Cho, and S.O. Kang, Hydrophilicity Control of Visible-Light Hydrogen Evolution and Dynamics of the Charge-Separated State in Dye/TiO2/Pt Hybrid Systems. Chemistry - A European Journal, 2012. 18(48): p. 15368-15381.

Choi, S.K., H.S. Yang, J.H. Kim, and H. Park, Organic dye sensitized $\mathrm{TiO} 2$ as a versatile photocatalyst for solar hydrogen and environmental remediation. Applied Catalysis $B$ Environmental, 2012. 121-122: p. 206-213.

19 Watanabe, M., H. Hagiwara, A. Iribe, Y. Ogata, K. Shiomi, A Staykov, S. Ida, K. Tanaka, and T. Ishihara, Spacer effects in metal-free organic dyes for visible-light-driven dye-sensitized photocatalytic hydrogen production. Journal of Materials Chemistry A, 2014. 2(32): p. 12952-12961.

20 Yu, F.T., S.C. Cui, X. Li, Y.Y. Peng, Y. Yu, K. Yun, S.C Zhang, J. Li, J.G. Liu, and J.L. Hua, Effect of anchoring groups on $\mathrm{N}$-annulated perylene-based sensitizers for dye-sensitized solar cells and photocatalytic $\mathrm{H}-2$ evolution. Dyes and Pigments, 2017. 139: p. 7-18

21 Thelakkat, M., Star-Shaped, Dendrimeric and Polymeric Triarylamines as Photoconductors and Hole Transport Materials for Electro-Optical Applications. Macromolecular Materials and Engineering, 2002. 287(7): p. 442-461.

Tiwari, A. and U. Pal, Effect of donor-donor- $\pi$-acceptor architecture of triphenylamine-based organic sensitizers ove $\mathrm{TiO} 2$ photocatalysts for visible-light-driven hydrogen production. International Journal of Hydrogen Energy, 2015. 40(30): p. $9069-9079$.
23 Li, X., S. Cui, D. Wang, Y. Zhou, H. Zhou, Y. Hu, J.-g. Liu, Y. Long, W. Wu, J. Hua, and H. Tian, New Organic DonorAcceptor- $\pi$-Acceptor Sensitizers for Efficient Dye-Sensitized Solar Cells and Photocatalytic Hydrogen Evolution under Visible-Light Irradiation. ChemSusChem, 2014. 7(10): p. 2879 2888 .

24 Dessi, A., M. Monai, M. Bessi, T. Montini, M. Calamante, A. Mordini, G. Reginato, C. Trono, P. Fornasiero, and L. Zani, Towards Sustainable H2 Production: Rational Design of Hydrophobic Triphenylamine-based Dyes for Sensitized Ethanol Photoreforming. ChemSusChem, 2018. 11(4): p. 793-805.

25 Aslan, E., M.K. Gonce, M.Z. Yigit, A. Sarilmaz, E. Stathatos, F. Ozel, M. Can, and I.H. Patir, Photocatalytic H2 evolution with a Cu2WS4 catalyst on a metal free D- $\pi$-A organic dyesensitized TiO2. Applied Catalysis B: Environmental, 2017. 210: p. 320-327.

26 Patir, I.H., E. Aslan, G. Yanalak, M. Karaman, A. Sarilmaz, M. Can, M. Can, and F. Ozel, Donor- $\pi$-acceptor dye-sensitized photoelectrochemical and photocatalytic hydrogen evolution by using Cu2WS4 co-catalyst. International Journal of Hydrogen Energy, 2019. 44(3): p. 1441-1450.

27 Aslan, E., M. Karaman, G. Yanalak, M. Can, F. Ozel, and I.H Patir, The investigation of novel D- $\pi$-A type dyes (MK-3 and MK-4) for visible light driven photochemical hydrogen evolution. Dyes and Pigments, 2019. 171: p. 107710.

28 Aslan, E., M. Karaman, G. Yanalak, H. Bilgili, M. Can, F. Ozel, and I.H. Patir, Synthesis of novel tetrazine based D- $\pi$-A organic dyes for photoelectrochemical and photocatalytic hydrogen evolution. Journal of Photochemistry and Photobiology A: Chemistry, 2020. 390: p. 112301.

29 Swinehart, D.F., The Beer-Lambert Law. Journal of Chemical Education, 1962. 39(7): p. 333.

30 Luo, G.-G., H. Lu, Y.-H. Wang, J. Dong, Y. Zhao, and R.-B. $\mathrm{Wu}$, A D- $\pi-\mathrm{A}-\pi-\mathrm{A}$ metal-free organic dye with improved efficiency for the application of solar energy conversion. Dyes and Pigments, 2016. 134: p. 498-505.

31 Cardona Claudia, M., W. Li, E. Kaifer Angel, D. Stockdale, and C. Bazan Guillermo, Electrochemical Considerations for Determining Absolute Frontier Orbital Energy Levels of Conjugated Polymers for Solar Cell Applications. Advanced Materials, 2011. 23(20): p. 2367-2371.

32 Margalias, A., K. Seintis, M.Z. Yigit, M. Can, D. Sygkridou, V. Giannetas, M. Fakis, and E. Stathatos, The effect of additional electron donating group on the photophysics and photovoltaic performance of two new metal free D- $\pi$-A sensitizers. Dyes and Pigments, 2015. 121: p. 316-327. 